International Journal of

Health, Medicine and

Nursing Practice

(IJHMNP)

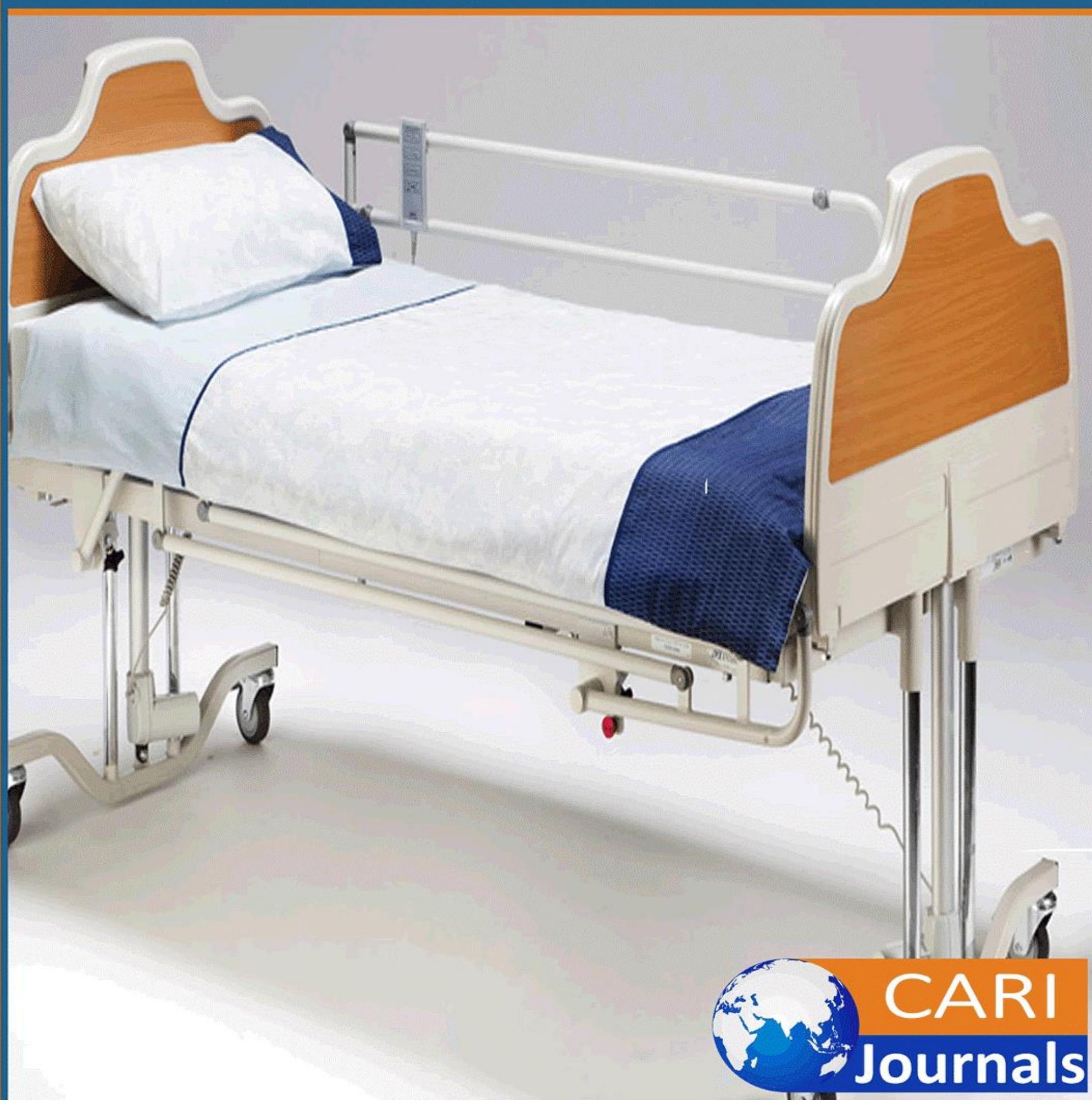




\title{
UPTAKE OF 'FREE' MATERNITY SERVICES AMONG WOMEN IN RONGAI SUB- COUNTY HOSPITAL, NAKURU COUNTY.
}

\author{
Kulei Stella Jepkoech \& Alice kemunto Maranga-Ondieki \\ Department of Nursing, Faculty of Health Sciences, Egerton University, P.O. Box 536-20115 \\ Egerton, Njoro, Kenya.
}

Corresponding Author: kuleistella@gmail.com

\begin{abstract}
.
Purpose: Subsidized delivery services aim to reduce both maternal and neonatal' morbidities and mortalities. The uptake in Kenya is still low at about $51 \%$. The objective of the study was to determine factors that influence utilization of subsidized delivery services.

Methodology: A cross-sectional study was used. The study was done in Rongai Sub-County hospital, Nakuru County. The population consisted of women seeking maternity services at Rongai Sub-County Hospital.

Results: About $60.8 \%$ of the respondents indicated they had knowledge while $39.2 \%$ of them indicated they did not have any knowledge on postnatal services.

Conclusion: Majority of women already have knowledge on availability of free hospital care service. Women are more likely to seek services that are close to them, long distance to health facilities prevents them from seeking the services.
\end{abstract}

Key words: free maternity, services among women, delivery services

\section{INTRODUCTION}

Maternal mortality is unacceptably high. About 295000 women died during and following pregnancy and childbirth in 2017. Sub-Saharan Africa and Southern Asia accounted for approximately $86 \%$ (254 000) of the estimated global maternal deaths in 2017. Sub-Saharan Africa alone accounted for roughly two-thirds (196 000) of maternal deaths. (WHO,2019).

Globally in the year 2018, 2.5 million children died in the first month of life , this estimates may be higher considering that low and middle income countries' findings are sometimes underreported; the WHO further estimates that approximately 7,000 neonatal deaths occur daily [WHO,2019, WHO,2020\}

In Kenya the maternal mortality rate is notably very high in comparison to other countries at 362 per 100,000live births. Of the 47 counties in the country fifteen contribute to $98 \%$ of the maternal mortality in the country and is listed as one among the 10 countries that account for $60 \%$ of global maternal deaths. This is despite the government coming up with remedial programmes to increase access to maternal health care including free maternity services in the Kenyan public health facility and expansion of the scope of the national health insurance scheme. The high 
International Journal of Health, Medicine and Nursing Practice

ISSN 2710-1150 (Online)

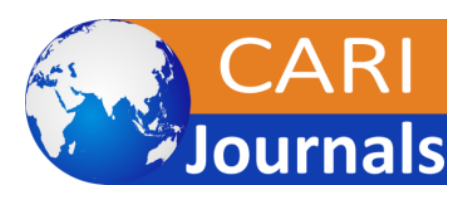

Vol.2, Issue No.3, pp $1-11,2020$

www.carijournals.org

mortality and morbidity rates have been attributed to a significant break in the continuum of care in the service-delivery strategy after delivery. (UNFPA, 2014) and home deliveries.

The aim of this study is to assess the utilization of 'free' maternity services in Rongai SubCounty hospital.

\section{MATERIALS AND METHODS}

\section{Study Design:}

A descriptive cross-section study design was used.

\section{Study area}

The study was carried out in Rongai Sub-County Hospital in Nakuru County. Nakuru County covers an area of 7,509.5 $\mathrm{KM}^{2}$. Its boarded by Baringo County to the North, Laikipia County to the Northeast, Kericho County to the Northwest, Nyandarua County to the East, Narok County to the West and Kajiado County to the South. The County is divided into 11 sub counties: Nakuru town east, Nakuru town west, Bahati, Rongai, Subukia, Kurusoi South, Gilgil, Naivasha, Molo and Njoro.

In the last census in 2009 Nakuru County had a total population of 1,603,325 it is the fourth largest County in Kenya after Nairobi, Kakamega and Kiambu in that order in terms of population. Rongai constituency had a population of 144,266 and Rongai ward having 30,965 people during the census.

\section{Study population}

The study population were women of reproductive age (15 to 49 years) who were expectant or just delivered.

\section{Sampling technique}

Systematic random sampling was used to select the sample.

\section{Inclusion criteria}

Pregnant women and women who had delivered who gave consent were included.

\section{Sample size determination}

Andrew Fisher's method (1998) was used to determine the size because my target population less than 10,000

$\mathrm{n}=\underline{\mathrm{Z}^{2} \mathrm{qp}}$

$$
\mathrm{d}^{2}
$$

where: $n=$ sample size estimate for a population target for $>10,000$

$$
\begin{aligned}
& \mathrm{Z}=\text { standard deviation using } 1.96 \text { at } 95 \% \text { confidence level } \\
& \mathrm{P}=\text { proportion of the population to have a particular character }(0.5) \\
& \mathrm{d}=\text { degree of accuracy }(0.5) \\
& \mathrm{q}=1-\mathrm{p}
\end{aligned}
$$


International Journal of Health, Medicine and Nursing Practice

ISSN 2710-1150 (Online)

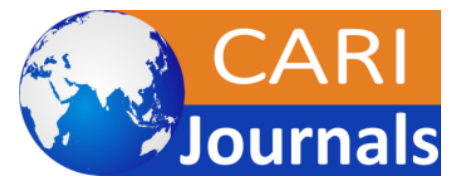

Vol.2, Issue No.3, pp $1-11,2020$

www.carijournals.org

Therefore:

$$
\mathrm{n}=\frac{1.96^{2} \times 0.5 \times 0.5}{0.05^{2}}
$$

$=384.16$

The sample size was determined using Andrew Fisher's method (1994) where the respondents was less than 10,000

Formula $\mathrm{nf}=$ desired sample size

$$
\begin{aligned}
\mathrm{n} & =\text { sample size }(384 \text { constant }) \\
\mathrm{N} & =\text { total population size }(140, \text { Rongai sub county Hospital Records, } 2017) \\
\mathrm{nf} & =\underline{384} \\
1 & +(384 / 140) \\
\mathrm{nf} & =\underline{384} \\
& 1+2.7 \\
\mathrm{nf} & =104
\end{aligned}
$$

\section{Data Collection}

Data was collected using a researcher administered questionnaire

\section{Data Analysis}

Data was collected, cleaned, coded and checked for completeness and entered into SPSS version 20. Quantitative data is presented in form of tables, graphs and pie charts.

\section{Ethical Considerations}

Approval was obtained from department of nursing, faculty of health science Egerton University and the medical superintendent of Rongai Sub-County hospital. An informed consent was obtained from all the participants. Confidentiality of the patients was maintained by omitting their names and giving them codes.

\section{RESULTS}

The response rate was (95)91.3\%.

\section{Respondents' demographic characteristics}

The study sought to determine the demographic characteristics of the respondents; age, gender, their highest level of education attained and their level of income. The study also determined the age of the respondents. $40 \%$ of the respondents were $25-29$ years, $20 \%$ of the respondents were $20-24$ years, $30 \%$ of the respondents were $30-39$ years, $5 \%$ of the respondents were 15-19years while $5 \%$ of the respondents were $>40$ years. 


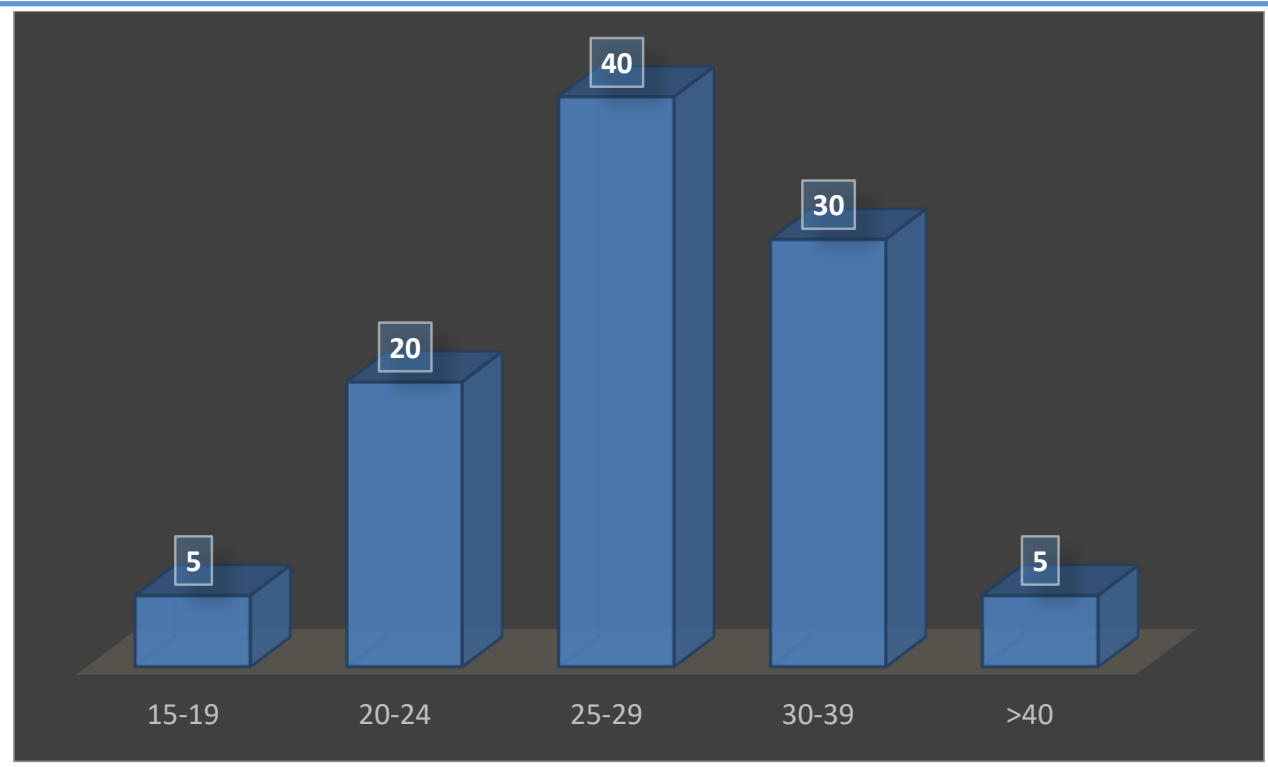

\section{Figure 1 Distribution of Respondents by Age.}

The study determined the Marital Status of the respondents. The results summarized in the table below. The findings indicate that the majority respondents were married and this was at $78 \%$, $11 \%$ were single mothers, $9 \%$ widowed and the remaining $2 \%$ of the respondents were divorced

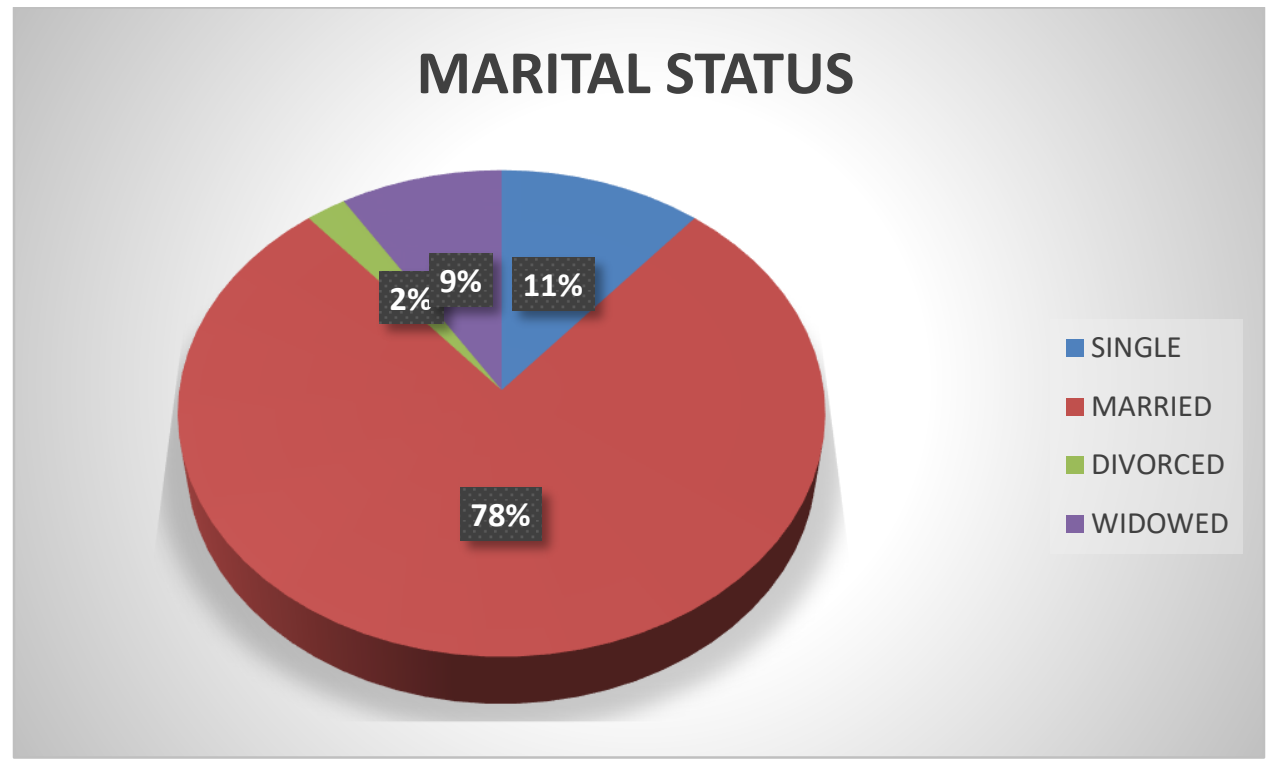

\section{Figure 2: Distribution of Respondents by Marital Status}

The results indicated that majority of the respondents $60.5 \%$ were living with their Partner and $39.5 \%$ were not living with their Partner.

\section{Distribution of respondents by Level of Education}


International Journal of Health, Medicine and Nursing Practice

ISSN 2710-1150 (Online)

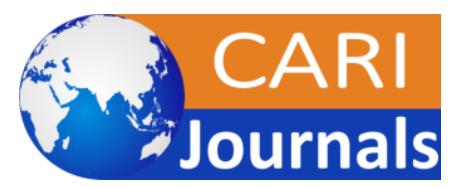

Vol.2, Issue No.3, pp $1-11,2020$

www.carijournals.org

The study determined the highest level of education attained by the respondents. From the findings the majority of the respondents $51.1 \%$ had attained secondary level, $21.7 \%$ had attained primary level, $22.1 \%$, had attained college/ university while $11.1 \%$ had no education.

Table 1: Distribution of Respondents by Level of Education

\begin{tabular}{lll}
\hline & Frequency & Percent \\
\hline PRIMARY & 20 & 21.7 \\
SECONDARY & 46 & 51.1 \\
COLLEGE/UNIVERSITY & 20 & 22.1 \\
NONE & 9 & 11.1 \\
Total & 95 & 100 \\
\hline
\end{tabular}

\section{Distribution of respondents by Religion}

The study determined the religion of the respondents. From the findings the majority of the respondents 52.3\% were seventh day Adventist, 44.4\%were Roman Catholic, $1.1 \%$ were Muslims while $2.2 \%$, had no religion.

Table 2: Distribution of Respondents by Religion

\begin{tabular}{lll}
\hline & Frequency & Percent \\
\hline NONE & 2 & 2.2 \\
MUSLIM & 1 & 1.1 \\
ROMAN CATHOLIC & 45 & 49.4 \\
SDA & 47 & 52.3 \\
Total & 95 & 100 \\
\hline
\end{tabular}

\section{Respondents by Employment Status}

The respondents were asked to indicate their Employment Status and the results were as captured in table 3 . The results indicated that among the respondents $33.3 \%$ were not employed, $55.6 \%$ were self-employed and $11.1 \%$ were employed.

Table 3: Distribution of Respondents by Employment Status

Frequency Percent


International Journal of Health, Medicine and Nursing Practice

ISSN 2710-1150 (Online)

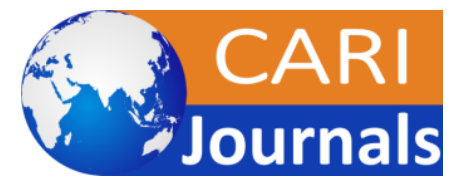

Vol.2, Issue No.3, pp 1 - 11, 2020

www.carijournals.org

EMPLOYED

10

11.1

SELF EMPLOYED

60.6

NONE

30

33.3

Total

95

100

\section{Number of pregnancies}

The study sought to establish the parity of the respondents. Majority of the respondents $58.89 \%$ indicated it was not their first pregnancy while $41.11 \%$ indicated it was their first pregnancy.

The study also sought to establish the number of pregnancies the respondent has had in total. From the results in table $41.11 \%$ indicated they had had one pregnancy, $18.9 \%$ indicated they had had 2 pregnancies, $33.33 \%$ of the respondents indicated 3 pregnancies while $3.33 \%$ of them indicated 4 times the rest had more than 4 children.

Table 4: Number of Pregnancies

\begin{tabular}{lcc}
\hline & Frequency & Percent \\
\hline Gravida 1 & 37 & 41.11 \\
Gravida 2 & 17 & 18.90 \\
Gravida 3 & 38 & 38.33 \\
Gravida 4 & 3 & 3.33 \\
Gravida 5 & 3 & 3.33 \\
TOTAL & $\mathbf{9 5}$ & $\mathbf{1 0 0}$ \\
\hline
\end{tabular}

\section{Number of Live Births}

The respondents were asked to indicate how many live births they have had altogether. $41.11 \%$ of the respondents indicated they have had 1 live birth, $18.9 \%$ indicated they have had 2 live births, $33.33 \%$ of the respondents indicated 3, 3.33\% indicated 4 live births while $3.33 \%$ of them indicated having other numbers of live births.

\section{Table 5: Number of Live Births}


International Journal of Health, Medicine and Nursing Practice

ISSN 2710-1150 (Online)

\begin{tabular}{llc} 
& Frequency & $\%$ \\
\hline 1 & 37 & 41.11 \\
2 & 17 & 18.9 \\
3 & 38 & 38.33 \\
4 & 3 & 3.33 \\
5 & 3 & 3.33 \\
Total & 95 & 100 \\
\hline
\end{tabular}

\section{Knowledge on free delivery Services}

The study sought to establish the respondents' knowledge on free delivery service. They were asked to indicate their knowledge and the results were as follows.

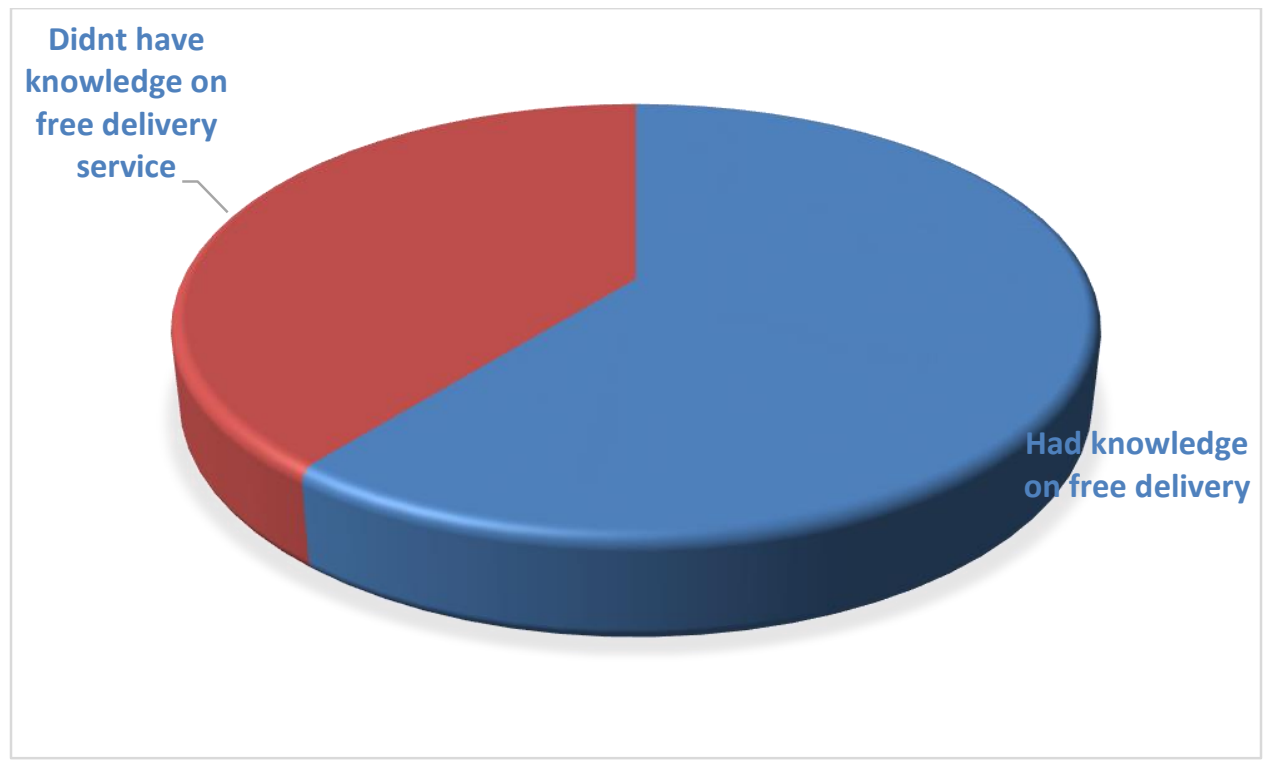

Figure 3: Knowledge on free maternity Services

About $60.8 \%$ of the respondents indicated they had knowledge while $39.2 \%$ of them indicated they did not have any knowledge on postnatal services.. 


\section{Information on 'free' maternity services}

When asked to indicate the sources of information they acquired free delivery service information from, $52 \%$ of the respondents indicated they got it from a nurse, $21 \%$ indicated it was from a midwife, $21 \%$ indicated from other sources while $6 \%$ indicated the information was acquired from a doctor.

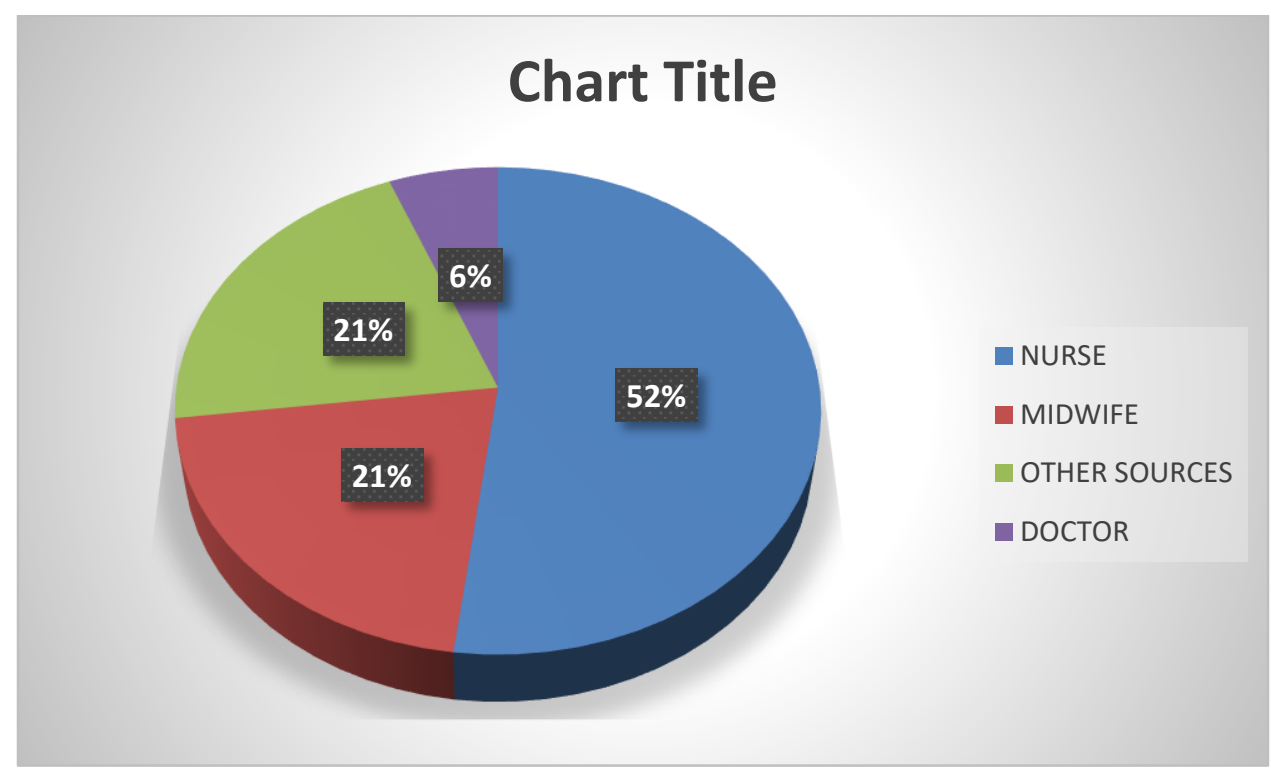

\section{Figure 4: Sources of Information}

\section{Cost of Maternity services}

The study sought to find out if the respondents paid for delivery service. $91.2 \%$ of them indicated they did not pay for the services while $8.8 \%$ indicated that they had to pay for the services. When asked how much they indicated they paid less than Ksh500.

\section{Distance to Health facility.}

When asked to indicate the distance to the nearest health facility, responses were given as shown in figure 5.

$70 \%$ of the respondents indicated it was 0 -5kilometers, $20 \%$ of the respondents indicated the distance was 6-10 kilometers while 10\% indicated it was more than 11 kilometers. 
International Journal of Health, Medicine and Nursing Practice

ISSN 2710-1150 (Online)

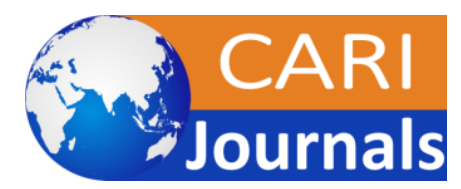

Vol.2, Issue No.3, pp $1-11,2020$

$\underline{\text { www.carijournals.org }}$

\section{Distance to nearest health facility}

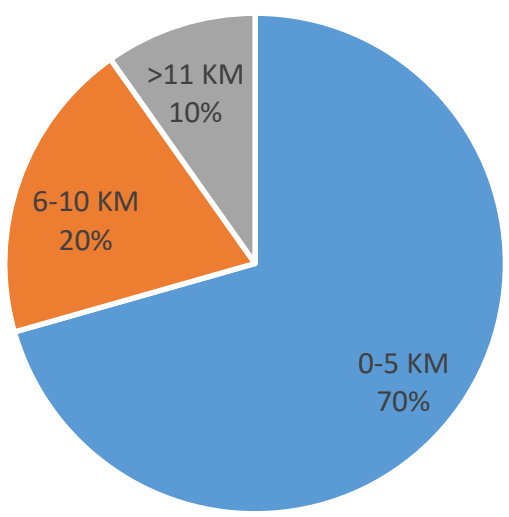

\section{Figure 5: Distance To Nearest Health Facility}

When asked to indicate whether they thought the distance was far or near, $74.9 \%$ of the respondents indicated that the distance was near while $25.1 \%$ of them indicated it was far. The mean for the statement was 1.254 while the standard deviation was 0.416 indicated in table 6 .

Table 6: Distance Near or Far

\begin{tabular}{lllll}
\hline & Frequency & Percent & Mean & Std. Deviation \\
\hline NEAR & 70 & 77.8 & 1.25 & 0.428 \\
FAR & 25 & 27.2 & & \\
Total & 95 & 100 & & \\
\hline
\end{tabular}

\section{Discussion}

Based on the study findings on the demographic characteristics, The younger the prospective mother, the less likely they will utilize free delivery care service, according to (Pandey et.al 2012; Sakala et al. 2011, these findings correspond to the findings of this study.

According to Sakala \& Kazembe (2011) 54\% of women with secondary school education were more likely to seek free delivery service, compared to $29 \%$ of women with no education. It has been established that education affects utilization of free maternity care services, concluding that educated mothers are more likely to utilize free maternity care services. This corresponds to this study's results where $45.1 \%$ had attained secondary level of education, $21.7 \%$ had attained primary level, $22.1 \%$, had attained college/ university while $11.1 \%$ had no education. 
Working women have better financial resources and thus will access free delivery service care. It is assumed that women who are employed will have enough finance to pay for transport and other indirect costs to access the service. The type of employment a woman is involved in determines her use of these services (Pandey et al, 2012). The responses of the respondents of this study indicated that majority of the respondents $55.6 \%$ were self-employed, $33.3 \%$ were not employed and $11.1 \%$ were employed.

Birth order is an important predictor in explaining the utilization of free maternity care services. Due to the uncertainty and the perception of risk associated with first pregnancies, women are more likely to seek medical attention for first-order births than for subsequent ones (Singh et al., 2013).

A lack of knowledge regarding the importance or benefits of hospital delivery among mothers, their families and the community, has been reported as one of the reasons for non-utilization of free delivery service (Jammah et al. 2011). About $60.8 \%$ of the respondents in this study indicated they had knowledge while $39.2 \%$ of them indicated they did not have any knowledge on postnatal services.

The ease of access to free delivery care services may be facilitated or hindered by the location and physical distance of the service from the client. When it is near, it enables mothers to have the means and knowledge of getting to those services which encourages the utilization of these vital medical service (Sharma, 2012). Distance has also been a factor of consideration in this study. When asked to indicate whether they thought the distance was far or near, $25.5 \%$ of the respondents of this study indicated that the distance to the health facility was far.

\section{Conclusion}

Younger women and mothers are likely not to seek free delivery care services as compared to the older women. Those with a higher level of education are more likely to seek postnatal care services than those without. Women with a source of income will seek free delivery care more as compared to those without.

Majority of women already have knowledge on availability of free maternityl care services. Women are more likely to seek services that are close to them, long distance to health facilities prevents them from seeking the services.

\section{Recommendations}

The Nakuru County government, department of health should intensify sensitization campaigns on the subsidized services to promote optimum utilization in health facilities.

\section{REFERENCES}

Jammah et al 2011. Factors influencing utilization of postnatal care services

Pandey, S, Lama, G, Lee, H. (2012) Effect of empowerment on women's utilization of health services: A case of Nepal. International Social Work.

Sakala B, Kazembe A (2011). Factors influencing the utilization of postnatal care at one week and six weeks among mothers at Zomba Central Hospital in Malawi. Ev-idence Based Midwifery, 9: 113-136. 
International Journal of Health, Medicine and Nursing Practice

ISSN 2710-1150 (Online)

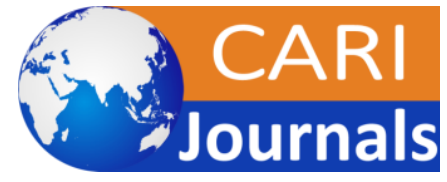

Vol.2, Issue No.3, pp $1-11,2020$

WwW.carijournals.org

Singh, P. K., Kumar, C., \& Singh, L. (2013). Factors associated with the utilization of maternal health care services among adolescent women in Malawi. Home Health Care Services Quarterly. doi:10.1080/01621424.2013.779354

Trends in maternal mortality: 2000 to 2017: estimates by WHO, UNICEF, UNFPA, World Bank Group and the United Nations Population Division. Geneva: World Health Organization; 2019

UNFPA-Kenya Counties with the Highest Burden of Maternal Mortality 13 August 2014

WHO. Newborn for Africa. Geneva: WHO; 2019.

WHO. Newborns Reducing Mortality. Geneva: World Health Organization; 2020 